\title{
INCORPORAÇÃO DE COLÁGENO DE RÃ EM MEMBRANAS DE CELULOSE BACTERIANA/ALOE VERA
}

\author{
D. J. de SOUZA ${ }^{1}$, K. CESCA ${ }^{1}$ e L. M. PORTO ${ }^{1}$ \\ ${ }^{1}$ Universidade Federal de Santa Catarina, Departamento de Engenharia Química e Engenharia de \\ Alimentos \\ E-mail para contato: drielle@intelab.ufsc.br
}

\begin{abstract}
RESUMO - Nos últimos anos, celulose bacteriana e Aloe vera têm sido considerados como biomateriais potencialmente promissores às áreas médica e cosmética, devido às suas propriedades para promover a cicatrização de feridas e à alta biocompatibilidade. Além disso, o gel de Aloe vera tem sido reportado pelas múltiplas propriedades benéficas, incluindo a capacidade de penetrar e anestesiar os tecidos e atuar como agente antiinflamatório. A fim de melhorar estas propriedades, a incorporação de colágeno tipo I de rã nas membranas de celulose bacteriana-Aloe vera foi estudada. $\mathrm{O}$ uso do colágeno de rã serve como uma alternativa ao bovino/suíno, uma vez que estes têm o potencial risco de infecção e de transmissão de doenças. Substratos de colágeno são conhecidos por influenciar as características do crescimento celular e também por modular vários aspectos do comportamento das células, como a adesão, proliferação e diferenciação. Membranas de celulose foram produzidas pela bactéria Gluconacetobacter hansenii e modificadas por gel de Aloe vera $(60 \%)$. O colágeno foi extraído da derme da rã por dois métodos distintos. Em seguida, este foi incorporado por imersão em solução ácida e a quantificação do mesmo foi realizada pelo método de Bradford. Os resultados de extração foram de 16-17 \% e os de incorporação variaram de 8 a $17 \%$, sugerindo a perspectiva do uso dessa fonte alternativa de colágeno em inúmeras aplicações.
\end{abstract}

\section{INTRODUÇÃO}

O polissacarídeo celulose é um biopolímero fascinante, sendo considerado como uma matériaprima sustentável e praticamente inexaurível. O interesse por recursos renováveis que possam ser utilizados no desenvolvimento de produtos inovadores à ciência, à medicina e à tecnologia ocasionou um renascimento da pesquisa interdisciplinar na área de celulose nos últimos anos, aumentando sua investigação e utilização (De Salvi, 2010).

A celulose bacteriana $(\mathrm{CB})$ é geralmente produzida em meio estático na forma de uma membrana gelatinosa na interface entre o ar e o meio de cultura. Representa um polímero natural inovador por combinar eficientemente as importantes e bem conhecidas qualidades da celulose com as características únicas dos nanomateriais (De Salvi, 2010; Hu, Catchmark, \& Vogler, 2013).

A vantagem de se utilizar CB reside em sua alta pureza e cristalinidade, fibrilas finas (menores que $130 \mathrm{~nm}$ ) com elevada área superficial, alta resistência mecânica e capacidade de retenção de água. 


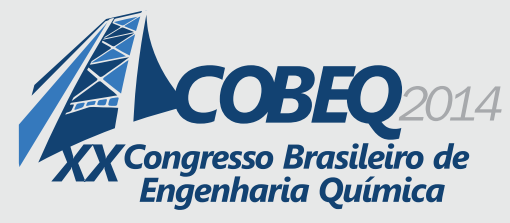

19 a 22 de outubro de 2014
Florianópolis/SC

A CB tem potencial para ser usada como um biomaterial comercial devido à sua biocompatibilidade, promoção da cicatrização de feridas, moldabilidade in situ e uma produção relativamente eficiente em termos de custo (De Salvi, 2010; Hong et al., 2006; Hu, Catchmark, \& Vogler, 2013).

A funcionalização da CB com materiais inorgânicos ou poliméricos abre novos caminhos para a fabricação de nanocompósitos multifuncionais com performances promissoras. A CB é utilizada como um molde para a preparação de nanocompósitos funcionais que reúnem excelentes propriedades da CB com os exibidos pelos nanomateriais típicos orgânicos ou inorgânicos. Destacam-se as propriedades ópticas, elétricas e magnéticas, bem como a atividade catalítica, antibacteriana e biomédica (Pedroso, 2009; Hu et al., 2014).

Buscando a multifuncionalidade e utilizando carboidratos complexos obtidos a partir de fontes naturais, segundo Ahlawat e Singh (2011), a Aloe vera tem se tornado promissora à saúde, com efeito medicinal e finalidade estética, considerando a aplicação na cicatrização de feridas, tratamento e redução dos danos de queimaduras e proteção contra danos de raios-x à pele. Além disso, o tratamento com gel de Aloe acelera a contração da ferida e aumenta a resistência à ruptura do tecido da cicatriz resultante, estimulando o crescimento de fibroblastos e a proliferação de colágeno neste tecido quando aplicado topicamente. Aloe tem efeito antimicrobiano e antitumoral, com propriedades antiinflamatória e imunomoduladora (Choi e Chung, 2003; Saini e Saini, 2011; Silva et al., 2013).

A CB é um material altamente poroso, que permite a transferência de macromoléculas, enquanto que do mesmo modo serve como uma barreira física eficaz contra qualquer infecção externa. Essa característica possibilita a modificação por gel de Aloe vera e também a incorporação de colágeno em sua rede de nanofibras (Chawla et al., 2009).

O colágeno é a proteína mais abundante no corpo humano e, principalmente, na pele. Apresenta boa compatibilidade comparado a outros polímeros naturais, sendo facilmente absorvível pelo corpo, com alta hidrofilicidade e baixa antigenicidade. Desempenha um papel importante na formação de tecidos e órgãos do corpo. Devido a essas características, sua aplicação na área biomédica e de bioengenharia tem crescido expressivamente (Lee et al., 2001; Li et al., 2004; Ferreira et al., 2012).

A associação de colágeno com outros biomateriais é necessária a fim de melhorar as propriedades físicas, químicas e biológicas, atingir a estabilidade do sistema e aprimorar os perfis de liberação de compostos incorporados, por exemplo (Ma et al., 2003; Powell e Boyce, 2006).

Para fins industriais, as principais fontes de colágeno estão limitadas aos de animais da terra, tais como bovinos e suínos. No entanto, o surto de febre aftosa, encefalopatia espongiforme bovina (BSE) e encefalopatia espongiforme transmissível (TSE) resultaram em ansiedade entre os usuários de produtos derivados de colágeno de origem animal terrestre. Além disso, em certas localidades, o colágeno extraído de fontes porcinas não pode ser usado como um componente de alguns alimentos, devido às restrições religiosas. Portanto, fontes alternativas de colágeno com riscos menores e que sejam acessíveis têm sido estudadas (Yan et al., 2008; Peng et al., 2010; Yan et al., 2012). 


\section{9 a 22 de outubro de 2014 \\ Florianópolis/SC}

A rã, como a maioria dos anfíbios, apresenta grande variedade de substâncias químicas no muco secretado pelas glândulas epidérmicas, as quais vêm sendo estudadas pela indústria farmacêutica na fabricação de antibióticos e outros medicamentos, constituindo-se num novo campo de estudo. A rãtouro é um animal ectotérmico, ou seja, seu metabolismo é dependente da temperatura ambiente. Além disso, é fonte de colágeno, sendo utilizada ainda como um tecido regenerativo extraordinário, de grande utilidade no tratamento de queimados, pois devido ao fato de ser translúcida, permite a passagem da luz, fundamental para a cicatrização (Ferreira et al., 2006; Qian et al., 2007).

O objetivo deste trabalho é realizar a incorporação de colágeno de rã em membranas de celulose bacteriana modificadas por gel de Aloe vera com a finalidade de produzir um biocompósito com características relevantes à aplicação em medicina regenerativa, engenharia tecidual e/ou cosmética.

\section{METODOLOGIA}

\subsection{Preparação das membranas de CB-Aloe vera}

Para a produção das membranas de CB-Aloe vera, o meio de cultura foi preparado contendo 25 g.L $\mathrm{L}^{-1}$ de manitol, 5 g.L $\mathrm{L}^{-1}$ de extrato de levedura e 3 g.L $\mathrm{L}^{-1}$ de peptona, todos diluídos em $1 \mathrm{~L}$ de água destilada. $\mathrm{O}$ pH da solução foi ajustado para 6,5 e, em seguida, esta foi autoclavada por 20 min a $121{ }^{\circ} \mathrm{C}$ (Recouvreux et al., 2011). Para a incorporação da Aloe vera na síntese in situ da CB, seguiuse a metodologia utilizada por Godinho (2014), na qual a porção de gel com fibras foi adicionada em concentração de $60 \%$ ao meio de cultura. As membranas de CB foram preparadas com a adição de $90 \%$ (v/v) do meio de cultura descrito anteriormente e $10 \%$ (v/v) de solução estoque de inóculo contendo a bactéria Gluconacetobacter hansenii (ATCC 23769). Na síntese das membranas, as culturas foram mantidas em placas de cultura de 24 poços (TPP, Suíça). Em cada poço, foi adicionado $1 \mathrm{~mL}$ da formulação. A formação das membranas ocorreu na interface ar/líquido durante 10 dias de cultura mantida a temperatura ambiente e sob condições estáticas de cultivo. Passados os 10 dias, as membranas de CB-Aloe vera foram retiradas das placas de cultura e, sucessivamente, purificadas e esterilizadas. Esta etapa consiste na remoção de células bacterianas e impurezas. Dessa forma, colocaram-se as membranas em frascos contendo $\mathrm{NaOH} 0,1 \mathrm{M}$, por $24 \mathrm{~h}$ a $50{ }^{\circ} \mathrm{C}$. Após este período, a solução alcalina foi retirada e as membranas foram lavadas com água destilada até atingir $\mathrm{pH}$ neutro. Em seguida, as membranas foram autoclavadas e estocadas a temperatura ambiente.

\subsection{Métodos de extração do colágeno de rã}

Método I: os procedimentos foram realizados a $4{ }^{\circ} \mathrm{C}$. A pele foi embebida em solução de ácido acético $0,5 \mathrm{M}(1: 3 \mathrm{~m} / \mathrm{v})$ por $72 \mathrm{~h}$ e o extrato foi centrifugado a $4800 \times \mathrm{g}$ por $1 \mathrm{~h}$. O sobrenadante foi coletado e o resíduo foi re-extraído pelo mesmo procedimento. Adicionou-se $\mathrm{NaCl}$ ao sobrenadante a fim de se obter uma concentração final de $0,8 \mathrm{M}$ e seguido pela precipitação de colágeno pela adição de $\mathrm{NaCl}$ (concentração final de $2,3 \mathrm{M})$ a $\mathrm{pH}$ neutro $(0,05 \mathrm{M}$ Tris- $\mathrm{HCl}, \mathrm{pH} 7,5)$. O precipitado foi coletado, re-dissolvido em ácido acético $0,5 \mathrm{M}$ e dialisado contra ácido acético $0,1 \mathrm{M}$ e água destilada por $72 \mathrm{~h}$ até pH neutro (Veeruraj et al., 2013). 


\section{9 a 22 de outubro de 2014 \\ Florianópolis/SC}

Método II: a pele de rã foi tratada com ácido acético $0,5 \mathrm{M}$ por $72 \mathrm{~h}$ sob agitação contínua a $4{ }^{\circ} \mathrm{C}$. $\mathrm{O}$ extrato foi centrifugado a $4800 \times \mathrm{g}$ por $1 \mathrm{~h}$. Adicionou-se $\mathrm{NaCl}$ ao sobrenadante a uma concentração final de 2,5 M, na presença de Tris- $\mathrm{HCl} 0,05 \mathrm{M}$, a pH 7,0. O precipitado resultante foi recolhido por centrifugação a $16000 \times \mathrm{g}$ por $1 \mathrm{~h}$. O pellet foi dissolvido em ácido acético $0,5 \mathrm{M}$, dialisado contra ácido acético $0,1 \mathrm{M}$ por 24 h e contra água destilada por $48 \mathrm{~h}$ (Zhang et al., 2014).

\subsection{Incorporação de colágeno de rã em membranas CB-Aloe vera}

Adaptando a metodologia de Zhijiang e Yang (2011), as membranas de CB-Aloe vera foram colocadas entre dois papéis-filtro a fim de remover a água livre. Em seguida, foram imersas em solução de 25 e $50 \%$ de colágeno de rã/ácido acético 0,5 M em condições ambiente por 24 h. Depois disto, o excesso da solução de colágeno foi removido usando papel-filtro.

\subsection{Quantificação de colágeno}

A fim de quantificar a extração e a incorporação do colágeno de rã, utilizou-se o método de Bradford. A técnica se baseia na determinação de proteínas totais que utiliza o corante de Coomassie Brilliant Blue BG-250 a fim de interagir com as macromoléculas protéicas que contém aminoácidos de cadeias laterais básicas ou aromáticas. Esta interação provoca o deslocamento do equilíbrio do corante para a forma aniônica, que absorve fortemente em $595 \mathrm{~nm}$. A quantificação foi realizada com base na curva de calibração utilizando BSA (albumina de soro bovino). O preparo da solução estoque (1,0 mg.mL $\left.\mathrm{mL}^{-1}\right)$ se deu pela solubilização de BSA em ácido acético 0,5 M, com diluições variando de 0-

$100 \mu \mathrm{g} \cdot \mathrm{mL}^{-1}$. A concentração de proteína foi obtida graficamente contra a absorbância correspondente resultando numa curva padrão, utilizando o software do espectrofotômetro Spectra Max Plus 384 (Molecular Devices, EUA), com o comprimento de onda ajustado em $595 \mathrm{~nm}$.

\subsection{Análise estatística}

Os valores médios obtidos a partir da análise da incorporação de colágeno nas membranas foram comparados entre os grupos experimentais prefixando-se o nível de significância em $95 \%$ $(\mathrm{p}<0,05)$. Foi aplicado o teste ANOVA seguido de Tukey para verificar a existência de diferenças estatisticamente significante entre os grupos.

\section{RESULTADOS E DISCUSSÕES}

Foram utilizados dois métodos de extração de colágeno da derme da rã, os quais se obtiveram o rendimento final de 16,16 e 17,49\%, respectivamente. Os dados foram obtidos pelo método de Bradford. Esses valores foram superiores aos encontrados pelos autores dos métodos adaptados, que foram de 9 e $13 \%$ para a extração de colágeno da pele de enguia e de água-viva, respectivamente.

Conforme Li et al. (2004) e (Sai e Babu, 2001), existem diferenças relevantes na pele dos anfíbios quando comparadas a outros animais vertebrados, como a composição dos aminoácidos, e isto pode ser atribuído às diferenças nas propriedades físico-químicas e à relação estrutural do colágeno com o habitat e a função de cada espécie. Isso está diretamente ligado à extração de 
colágeno da pele. A pele da rã não foi solubilizada completamente em ácido acético, o que corrobora com a literatura (Li et al., 2004). A realização dos procedimentos a $4{ }^{\circ} \mathrm{C}$ é essencial para prevenir o crescimento de bactérias e também manter a forma nativa do colágeno.

No que tange às diferenças dos métodos, para o I adaptado de Veeruraj et al. (2013), foi utilizada uma re-extração aliada à adição de $\mathrm{NaCl}$ para precipitação inicial, seguida da adição do sal dissolvido em tampão para precipitação final. Essa precipitação dupla por adição de sal neutro é geralmente usada nestes casos, para que haja uma maior interação entre as moléculas da proteína, diminuindo a solubilidade no meio aquoso (Souza et al., 2013). Já o método II, adaptado de Zhang et al. (2014), extraiu-se o colágeno apenas uma vez e ocorreu apenas uma precipitação. Comparando os valores obtidos, observa-se que não é vantajoso em termos de custo e tempo de extração realizar o método I, já que o método II obteve um rendimento final maior.

A fim de avaliar a incorporação do colágeno extraído, as membranas de CB-Aloe vera foram imersas em solução ácida com concentrações de 25 e $50 \%$ de colágeno. Após esse tempo determinado, as membranas foram retiradas das placas e coletou-se a solução resultante a fim de quantificar a incorporação. Pelo método de Bradford, fez-se a leitura utilizando o software do espectrofotômetro Spectra Max Plus 384 (Molecular Devices, EUA), obtendo-se um gráfico que relaciona a porcentagem de incorporação de colágeno pelas membranas de $\mathrm{CB}$-Aloe vera com o seu respectivo método e concentração de colágeno, conforme Figura 1 a seguir.

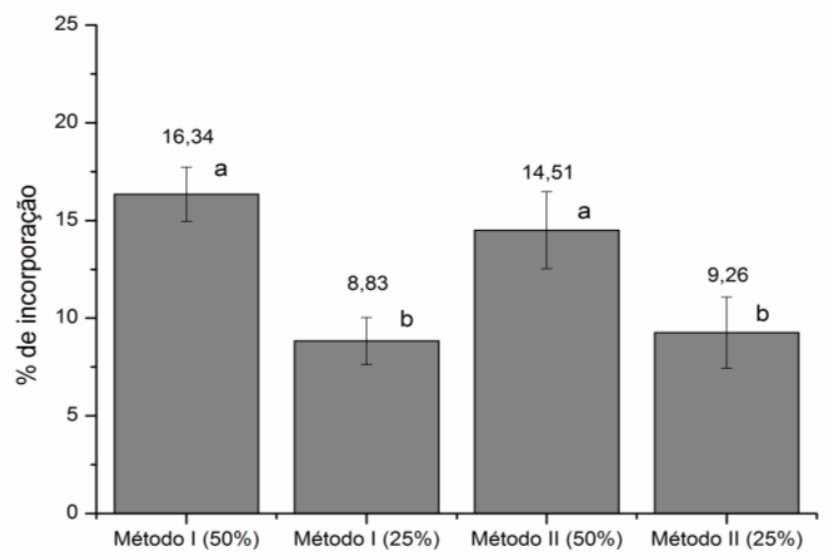

Figura 1 - Porcentagem de incorporação de colágeno em membranas de celulose bacteriana modificadas por gel de Aloe vera para os métodos I e II nas concentrações de 25 e $50 \%$ de colágeno em solução ácida.

Observou-se que a concentração de colágeno adicionada foi diretamente proporcional à incorporação. Para as concentrações de $25 \%$, os resultados foram de $8-9 \%$ e para as de $50 \%$ foram de 16-17\%. Realizando o teste ANOVA seguido de Tukey, observou-se que os valores são significativamente diferentes.

Macroscopicamente, foi possível observar homogeneidade nas membranas e que a presença de colágeno as tornaram mais densas e esbranquiçadas, comparadas à transparência e ao aspecto poroso da membrana pura. Isto se deve à presença de colágeno entre as fibras de celulose, como citado por 
Zhijiang e Yan (2011), que observaram uma modificação estrutural devido à formação de ligações entre o colágeno e a celulose. Esse recobrimento de colágeno nas fibras de celulose é promissor ao crescimento celular para aplicações biomédicas, por exemplo.

\section{CONCLUSÕES}

Neste trabalho, pode-se demonstrar que é possível extrair colágeno da derme da rã-touro, assim como já foi publicado na literatura anteriormente, com rendimentos similares. Os resultados obtidos quanto à incorporação variaram de 8 a $17 \%$. Ressalta-se a promissora multifuncionalização da celulose bacteriana associada à Aloe vera e ao colágeno na produção de um biocompósito aplicável na engenharia tecidual, haja vista as propriedades dos compostos envolvidos.

\section{REFERÊNCIAS}

AHLAWAT, K. S.; SINGH, K. B. Processing, food applications and safety of aloe vera products: review. J Food Sci Tech, v. 48, n. 5, p. 525-33, 2011.

CHAWLA, P. R.; BAJAJ, I. B.; SURVASE, S. A.; SINGHAL, R. S. Microbial Cellulose: Fermentative Production and Applications. Food Tech Biotech, v. 47, n. 2, p. 107-124, 2009.

CHOI, S.; CHUNG, M.-H. A Review on the Relationship between Aloe Vera Components and Their Biologic Effects. Semin Integr Med, v. 1, n. 1, p. 53-62, 2003.

FERREIRA, A. M.; GENTILE, P.; CHIONO, V.; CIARDELli, G. Collagen for bone tissue regeneration. Acta Biomater, v. 8, n. 9, p. 3191-3200, 2012.

FERREIRA, D. S.; JÚNIOR, P. E. A.; MAIA, C. S.; SILVA, W. E.; FRANÇA, D. F.; MORAES, E. F.; TEIXEIRA, A. A. C. Caracterização histológica da pele da rã-touro (Rana Catesbeiana, Shaw 1802). Biológico, v. 68, p. 239-243, 2006.

GODINHO, J. F. Hidrogéis de Celulose Bacteriana Incorporados com Frações de Aloe vera. (Mestrado). Departamento de Engenharia Química e Engenharia de Alimentos, Universidade Federal de Santa Catarina. 2014.

HU, W.; CHEN, S.; YANG, J.; LI, Z.; WANG, H. Functionalized bacterial cellulose derivatives and nanocomposites. Carbohydr Polym, v. 101, p. 1043-60, 2014.

LEE, C. H.; SINGLA, A.; LEE, Y. Biomedical applications of collagen. Int J Pharm, v. 221, n. 1-2, p. 1-22, 2001.

LI, H.; LIU, B. L.; GAO, L. Z.; CHEN, H. L. Studies on bullfrog skin collagen. Food Chem, v. 84, n. 1, p. 65-69, 2004.

MA, L.; CHANGYOU, G.; ZHENGWEI, M.; JIE, Z.; JIACONG, S.; XUEQING, H.; CHUNMAO, H. Collagen/chitosan porous scaffolds with improved biostability for skin tissue engineering. Biomaterials, v. 24, n. 26, p. 4833-4841, 2003.

PEDROSO, M. V. G. Estudo comparativo de colágeno hidrolisado e comercial com adição de PVA. (Mestrado). Instituto de Química. Universidade de São Paulo. 2009. 
PENG, Y. Y.; GLATTAUER, V.; RAMSHAW, J. A.; WERKMEISTER, J. A. Evaluation of the immunogenicity and cell compatibility of avian collagen for biomedical applications. J Biomed Mater Res A, v. 93, n. 4, p. 1235-44, 2010.

POWELL, H. M.; BOYCE, S. T. EDC cross-linking improves skin substitute strength and stability. Biomaterials, v. 27, n. 34, p. 5821-7, 2006.

QIAN, Z. J.; DAI, N. N.; K., K. S. Isolation and Characterization of Collagen from Skin of Bullfrog, Rana catesbeiana Shaw. J Fish Aqua. Sci, v. 10, p. 53-59, 2007.

RECOUVREUX, D. O. S.; RAMBO, C. R.; BERTI, F. V.; CARMINATTI, C. A.; ANTONIO, R. V.; PORTO, L. M. Novel three-dimensional cocoon-like hydrogels for soft tissue regeneration. Mat Sci Eng C-Mater, v. 31, n. 2, p. 151-157, 2011.

SAI, K. P.; BABU, M. Studies on Rana tigerina skin collagen. Comp Biochem Physiol B Biochem Mol Biol, v. 128, n. 1, p. 81-90, 2001.

SAINI, D. K.; SAINI, M. R. Evaluation of radioprotective efficacy and possible mechanism of action of Aloe gel. Environ Toxicol Pharmacol, v. 31, n. 3, p. 427-35, 2011.

SILVA, S. S.; POPA, E. G.; GOMES, M. E.; CERQUEIRA, M.; MARQUES, A. P.; CARIDADE, S. G.; TEIXEIRA, P.; SOUSA, C.; MANO, J. F.; REIS, R. L. An investigation of the potential application of chitosan/aloe-based membranes for regenerative medicine. Acta Biomater, v. 9, $\mathrm{n}$. 6, p. 6790-7, 2013.

SOUZA, I. C. L.; DO NASCIMENTO, M. F.; DE SOUZA, R. G.; NETA, J. C. D. S.; COSTA, L. P.; CARDOSO, J. C.; DE ALBUQUERQUE-JÚNIOR, R. L. C. Effect of the maltodextrin-induced chemical reticulation on the physical properties and healing potential of collagen-based membranes containing Brazilian red propolis extract. I J med Med Sci, v. 5, n. 12, p. 514-524, 2013.

VEERURAJ, A.; ARUMUGAM, M.; BALASUBRAMANIAN, T. Isolation and characterization of thermostable collagen from the marine eel-fish (Evenchelys macrura). Process Biochem, v. 48, n. 10, p. 1592-1602, 2013.

YAN, M.; BAFANG, L.; XUE, Z.; GUOYAN, R.; YONGLIANG, Z.; HU, H.; XIUKUN, Z.; LI, C.; YAN, F. Characterization of acid-soluble collagen from the skin of walleye pollock (Theragra chalcogramma). Food Chem, v. 107, n. 4, p. 1581-1586, 2008.

YAN, M.; LI, B.; ZHAO, X.; QIN, S. Effect of concentration, $\mathrm{pH}$ and ionic strength on the kinetic self-assembly of acid-soluble collagen from walleye pollock (Theragra chalcogramma) skin. Food hydrocolloid, v. 29, n. 1, p. 199-204, 2012.

ZHANG, J.; RUI, D.; LEI, H.; YUJIE, S.; M., R. J. Characterisation of acid-soluble and pepsinsolubilised collagen from jellyfish (Cyanea nozakii Kishinouye). Food Chem, v. 150, p. 22-26, 2014.

ZHIJIANG, C.; YANG, G. Bacterial Cellulose Collagen Composite: Characterization and First Evaluation of Cytocompatibility. J Appl Polymer Sci, v. 120, p. 2938-2944, 2011. 